\title{
Development of flood probability charts for urban drainage network in coastal areas through a simplified joint assessment approach
}

\author{
R. Archetti ${ }^{1}$, A. Bolognesi ${ }^{1}$, A. Casadio ${ }^{2}$, and M. Maglionico ${ }^{1}$ \\ ${ }^{1}$ DICAM University of Bologna, viale Risorgimento 2, 40136 Bologna, Italy \\ ${ }^{2}$ HERA Rimini, Via del Terrapieno 25, 47900 Rimini, Italy
}

Received: 8 April 2011 - Published in Hydrol. Earth Syst. Sci. Discuss.: 15 April 2011

Revised: 14 September 2011 - Accepted: 6 October 2011 - Published: 11 October 2011

\begin{abstract}
The operating conditions of urban drainage networks during storm events depend on the hydraulic conveying capacity of conduits and also on downstream boundary conditions. This is particularly true in coastal areas where the level of the receiving water body is directly or indirectly affected by tidal or wave effects. In such cases, not just different rainfall conditions (varying intensity and duration), but also different sea-levels and their effects on the network operation should be considered. This paper aims to study the behaviour of a seaside town storm sewer network, estimating the threshold condition for flooding and proposing a simplified method to assess the urban flooding severity as a function of climate variables. The case study is a portion of the drainage system of Rimini (Italy), implemented and numerically modelled by means of InfoWorks CS code. The hydraulic simulation of the sewerage system identified the percentage of nodes of the drainage system where flooding is expected to occur. Combining these percentages with both climate variables' values has lead to the definition of charts representing the combined degree of risk "rainfall-sea level" for the drainage system under investigation. A final comparison between such charts and the results obtained from a one-year rainfall-sea level time series has demonstrated the reliability of the analysis.
\end{abstract}

\section{Introduction}

Urban sites in coastal areas are particularly vulnerable to flooding both as a result of storm surge (and wave run-up and overtopping effects) and as a result of heavy rainfalls on the inland tributary catchment. An integrated approach in managing the risk of coastal flooding in urban areas is therefore

Correspondence to: A. Bolognesi

(and.bolognesi@unibo.it) essential to effectively understand the operating conditions of urban drainage systems and their hydraulic critical state.

It is well known that the coastal areas and urban areas located along the coastline, especially in the case of particularly low lying areas, are subjected to episodes which originate both from rainfall and from the sea.

The episodes of flooding from the sea are mainly due to storm surge (sea rise due to waves and wind). These flooding scenarios together with the high human pressure through uses of the coastal areas, lead to coastal hazards in coastal areas.

Wave transformations in the area close to the shoreline involve complex processes, but are of fundamental importance for the hydrodynamic and morphodynamic modelling of the land - sea interface. Levels reached by the sea on the shoreline during a storm are the sum of different contributions, basically summarized in: astronomical tide, storm surge, wave set-up. The first is easily forecasted. The second is caused primarily by high winds pushing on the sea surface: the wind causes the water to pile up higher than the ordinary sea level. The third occurs in the area between the breaker zone and the shore and reaches values far from negligible. Various empirical and numerical formulations are available in the scientific literature for the wave set-up, which often rely on simplified assumptions regarding the shape and type of seabed.

Moreover, the presence of coastal defence structures changes the dynamics in the coastal zone, requiring careful modelling of the wave set-up, due to an accumulation of water during storms between the parallel structures and the beach (known as piling up, Cappietti et al., 2006), which often leads to a wave reduction, but an increase in local sea water levels.

Combined waves and storm surge is the cause of wave overtopping which leads to flooding, of which the disastrous consequences are well known, but extreme overtopping events throw water over the crest with considerable velocities imposing serious hazards to both people and infrastructure. 


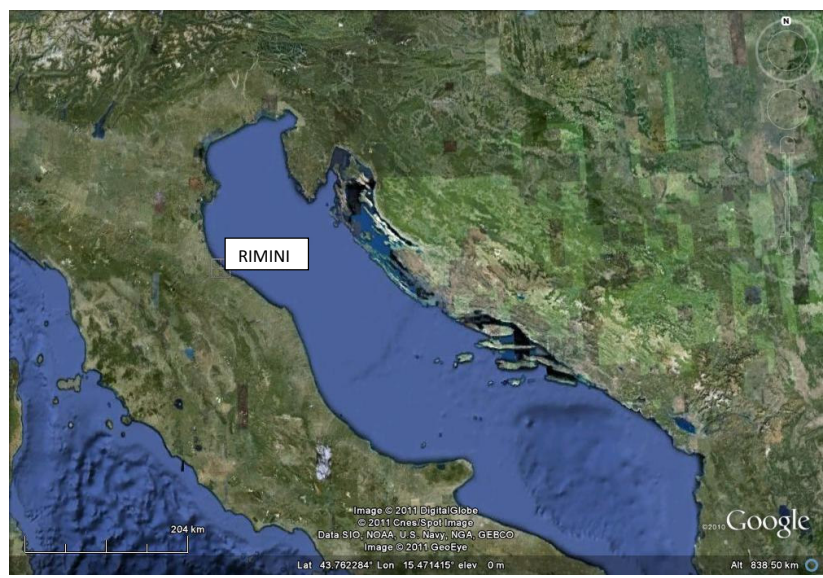

Fig. 1. Study site location.

Difficult decisions are therefore required of those who have responsibility for managing coastal areas, to choose the types of intervention for their protection. Coastal flood defences can mitigate inundation risk, by reducing sea and storm surge energy by enlarging the beaches (nourishments) or dissipating energy by hard structures (groynes, detached breakwaters, barriers), or the combination of the two (Archetti, 2009; Kroon et al., 2007). Moreover, even if the flooding risk from the sea can be controlled or reduced, when the sea is the receiving water body of an urban drainage system or, in general, when its level acts as the downstream boundary condition, the drainage system's hydraulics may be significantly affected, leading to critical states even under apparently not exceptional conditions (if considered individually).

Recent developments in computational technology allowed for deepening the aspects of flooding in the traditional codes for the simulation of urban drainage networks. They can be used in order to predict the most critical points of the network, either in terms of flooding event magnitude, or accounting for the importance and vulnerability of a certain specific point.

Some of the widely adopted numerical simulation tools for urban drainage networks, like MOUSE (Danish Hydraulic Institute), InfoWorks CS (Innovyze Ltd) and SWMM (Huber and Dickinson, 1988), directly or indirectly allow for establishing a relationship between rainfall and flooding.

Urban flooding in coastal urban areas may be caused by more than one single climatic source. We can highlight "sea sources" (sea levels and storm surges), "inland sources" (rainfall and rainfall-runoff processes) and in case the urban site lies close to a river (river mouth) there could be also "river sources" (river level). All these sources and their effects are often treated separately, so coastal protection experts and maritime hydraulics focus on the probability that the sea will reach certain levels (jointly considering the two variables sea level and storm surge), while those dealing with

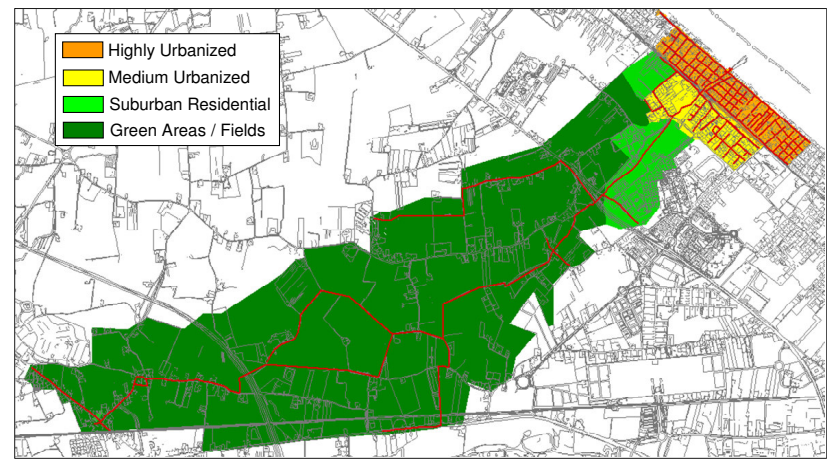

Fig. 2. Land use for the whole catchment drained by Sortie channel.

urban drainage networks, in order to define an outfall boundary condition, will probably consider a certain representative sea level, so to cautiously analyze possible backwater effects and relative flooding problems.

Since each of the previously mentioned sources exhibits its own significant variability, it appears essential to tackle the problem by carrying out an integrated analysis of the contemporary phenomena that may cause flooding in urban coastal areas. This is related to the joint probability of the two phenomena, i.e. the probability that two or more conditions occur at the same time (Tawn and Vassie, 1990; Hawkes et al., 2002, 2008; Hawkes, 2008).

The purpose of this paper is to show an approach that can be followed in the joint study of rainfall and sea level conditions. Basing on a real case study, the way the combination of variables "rainfall-sea level" lead to flooding effects in a coastal urban area, is hereinafter presented by defining charts representing the rainfall-sea level combined degree of risk.

\section{The case study}

The site chosen as the case study is a portion of the drainage network serving the northern area of the Municipality of Rimini (Italy), along the Adriatic coast (Fig. 1). The drained catchment has a total area of approximately 540 ha and consists of two distinct parts: a band close to the urbanized coast, where the drained area is approximately 60 ha and a remaining part, considerably less urbanized, which extends about $6 \mathrm{~km}$ inland.

The urban part could be further divided into two different zones: a densely urbanized area, about 250 meters wide, lying between the railway line Rimini-Ravenna and the coastline and some lower-density housing immediately upstream of the railway (Fig. 2). Both of these urban areas are almost completely flat (negligible slope) and their ground elevation is never higher than $3 \mathrm{~m}$ a.s.l. (above sea level). The upstream portion of the basin is instead almost entirely made up of natural terrain, with average slopes close to $0.5 \%$ (Fig. 3). 

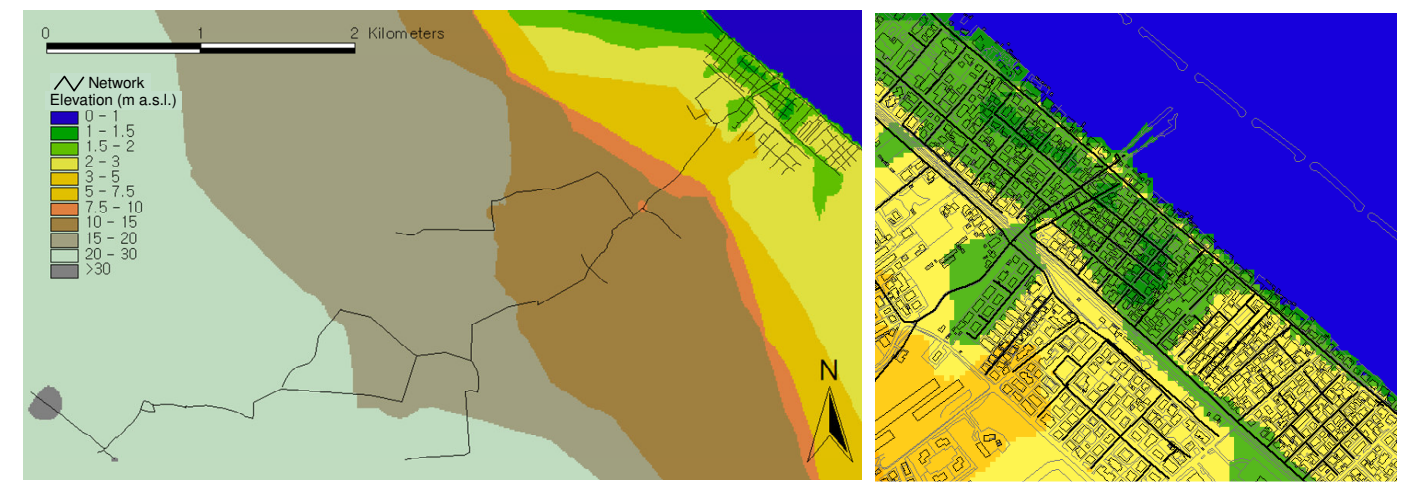

Fig. 3. Ground elevation of the entire catchment (left panel); detail of the urbanized area along the coastline (right panel).

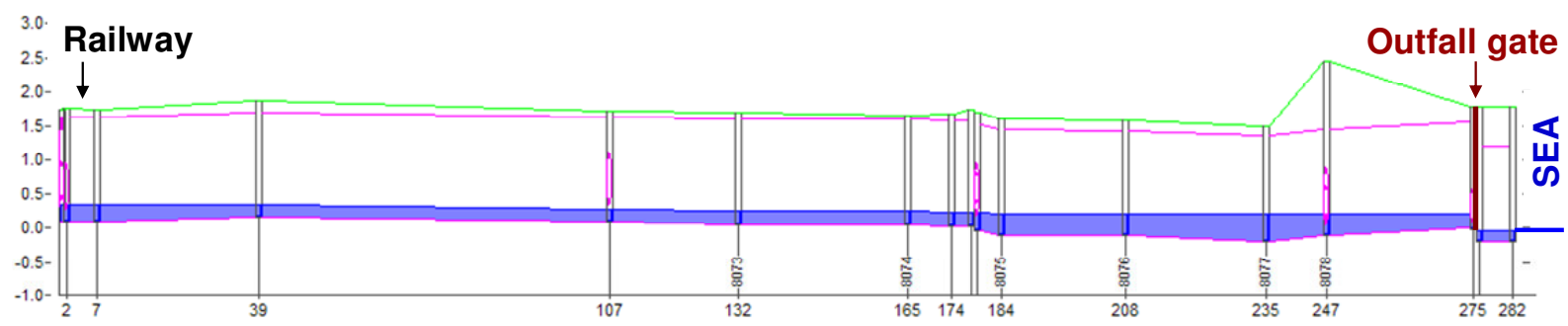

Fig. 4. Sortie channel: longitudinal profile of the final stretch (distances in $\mathrm{m}$, elevations in ma.s.1.).

The drainage network in the upstream part consists mostly of a network of natural ditches and drains, including short stretches of closed conduits. The main drain (called Sortie), once it enters the urbanized area (about $300 \mathrm{~m}$ upstream of the railway), flows in a closed rectangular box conduit, whose dimensions are $355 \times 150 \mathrm{~cm}$, with an almost zero slope (Fig. 4). Due to some sparse household connections in the upstream part, Sortie acts as a combined (storm and wastewater) sewer, while the urbanized area is served by a separate sewer network, where Sortie is the trunk main for the storm separate network. Close to the outfall, Sortie exhibits invert levels slightly lower $(-0.19 \mathrm{~m})$ than mean sea level, and since (for the small amount of wastewater coming from upstream) it is a combined sewer conduit, a sluice gate avoiding sewage spill into the sea and a pumping station (flow approx. equal to $501 \mathrm{~s}^{-1}$ ) are required.

The gate is operated remotely via a remote control system and its opening is regulated by an automatic control based on water level on the upstream side. When this level exceeds a preset threshold, the gate is open (duration of operation: approximately $2-3 \mathrm{~min}$ ) putting the drainage system in communication with the sea. Assessment of the influence that the sea level has on the operation of the network during rainfall is of fundamental interest.

\subsection{General characteristics of the climate near the case study site}

Excursion in sea levels is due to different phenomena that, once combined, may lead to significant variations. The sea levels are measured at the Porto Corsini (near Ravenna) tide gauge, located inside the harbour area and belonging to the network of SIMN-APAT (National Hydrographic Tidal Service). In this area the tidal range is generally between 30 and $80 \mathrm{~cm}$ (microtidal regime). The semidiurnal tides are the most important and the rising tide that enters the estuary has a shorter duration but greater speed compared to the backwater tidal wave, which propagates more slowly and in a longer time. The highest tides were recorded during the spring tide. During winter months storm surges amplify the tide, causing a rise in sea level of up to $100 \mathrm{~cm}$. A local tide gauge is located in the Rimini channel, adjacent to the Sortie. Data collected here measure the sea water level at the drainage network outfall. The measure is the sum of the different contributions to the sea water level: the astronomical tide and the storm surge, as well as the wave set up and pilling up by the breakwaters located in front of the shoreline (Fig. 5), which can reach not negligible values.

An updated extreme event analysis of the sea water level measured in Porto Corsini has been recently performed by Masina and Ciavola (2011). According to the existing relationship between Porto Corsini and Rimini tide gauges, it was possible to estimate the extreme sea water level at Sortie (Table 1). 
Table 1. Extreme values for rainfall intensity and sea water level at Sortie, as a function of return period.

\begin{tabular}{rccc}
\hline $\begin{array}{c}\mathrm{Tr} \\
\text { [years] }\end{array}$ & $\begin{array}{c}30 \mathrm{~min} \\
\text { rainfall int. } \\
\left(\mathrm{mm} \mathrm{h}^{-1}\right)\end{array}$ & $\begin{array}{c}2 \mathrm{~h} \\
\text { rainfall int. } \\
\left(\mathrm{mm} \mathrm{h}^{-1}\right)\end{array}$ & $\begin{array}{c}\text { Swl } \\
\text { Sortie } \\
{[\mathrm{m}]}\end{array}$ \\
\hline 2 & 38.1 & 15.3 & 1.21 \\
5 & 50.8 & 21.5 & 1.34 \\
10 & 59.5 & 25.9 & 1.43 \\
20 & 68.2 & 30.4 & 1.51 \\
50 & 79.8 & 36.6 & 1.62 \\
100 & 88.9 & 41.5 & 1.71 \\
\hline
\end{tabular}

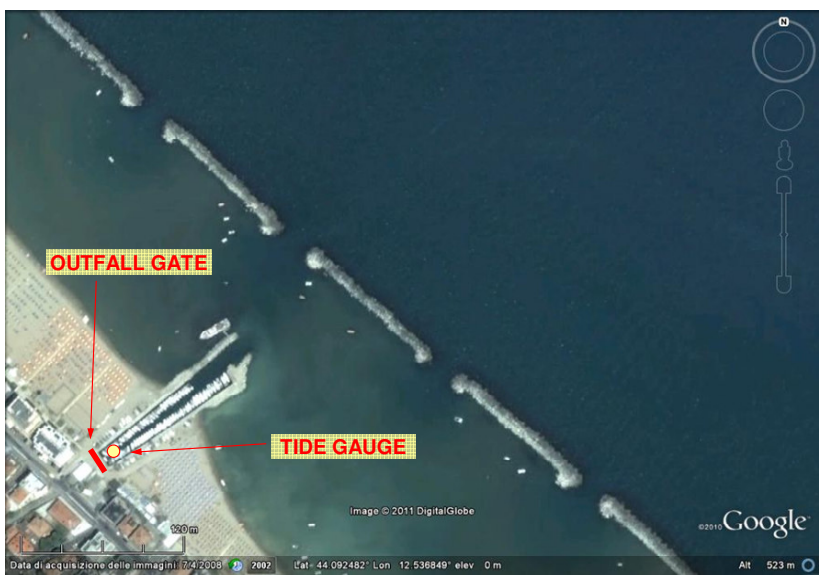

Fig. 5. Drainage network outfall and tide gauge location.

Concerning rainfall climate, Rimini has a humid subtropical climate, characterized by hot, humid summers and cool winters: "Cfa" according to the revised version of Köppen climate classification (Peel et al., 2007). The average yearly rainfall based on 1971-2000 data series is equal to $655 \mathrm{~mm}$, with a mean of 77 events $(>=1 \mathrm{~mm}$ ) occurring each year. The average hourly rainfall intensity (based on 2001-2010 data) is slightly above $4 \mathrm{~mm} \mathrm{~h}^{-1}$, while the maximum hourly rainfall for return period equal to 10 years is about $43 \mathrm{~mm} \mathrm{~h}^{-1}$. The extreme rainfall intensity values for the considered durations have been estimated according to the procedure developed by Di Baldassarre et al. (2006).

Table 1 summarizes the rainfall intensity and sea water level extreme values as a function of the return period.

The wave climate off the coast of Rimini is mainly characterized by events from the NE (Bora) and SE (Scirocco). While the former are more intense (Cesini et al., 2004; Martucci et al., 2010), critical conditions often leading to high sea levels on the coast are caused by the latter. The directional distribution of wave heights (Fig. 6) shows typical features of the northern Adriatic climate: the more frequent wave condition is from the SE (Scirocco) often associated with higher

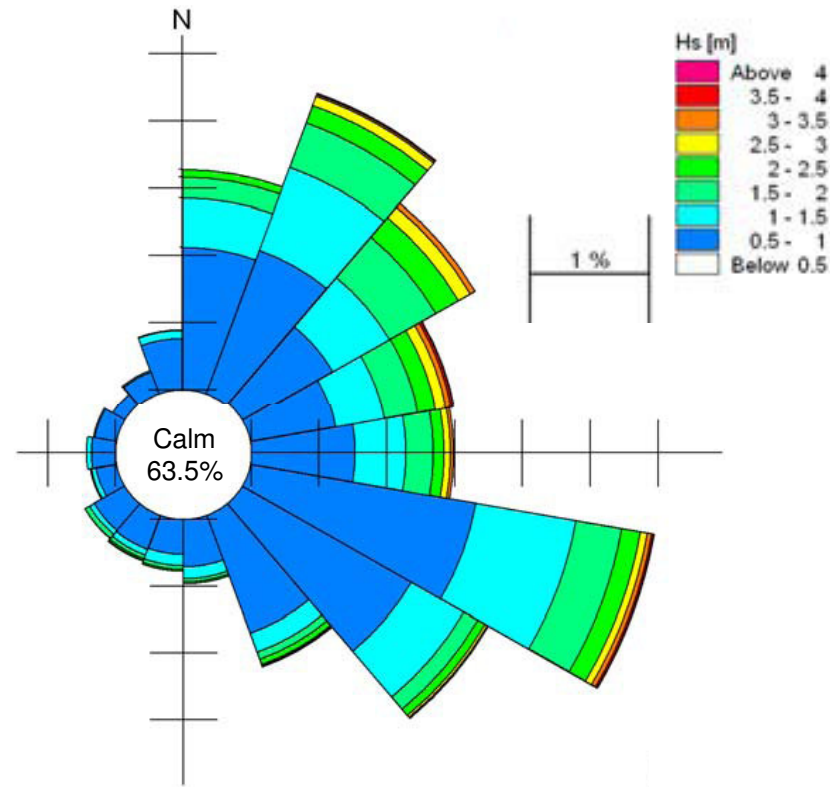

Fig. 6. Wave heights directional distribution offshore the study site.

sea levels and the most intense are from the NE (Bora). The highest waves (greater than $3 \mathrm{~m}$ ) come primarily from N-NE (Bora).

\subsection{Data availability and numerical model implementation}

The combined analysis of the hydraulic vulnerability due to rainfall and storm surge events in urban coastal areas requires a large amount of information and their combination. Particular relevance must be given to information concerning climatic variables, network geometry and possibly a detailed elevation model for the area potentially subject to flooding.

The drainage network and its main element "Sortie" have been reproduced and simulated by means of the numerical model InfoWorks CS (Innovyze Ltd). The hydrological module of the model receives rainfall time series input and performs rainfall-runoff transformation through a double linear reservoir. Runoff is then routed inside the network conduits by means of complete De Saint Venant equations. The software includes also a Real Time Control module, which allowed for simulating the outfall gate control logic accounting for the sea level (on the downstream side of the gate) and the Sortie water depth (right upstream of the gate).

Network data have been provided by HERA (local water utility), in detail:

- network layout, conduit size and shape and some invert levels are taken by HERA GIS;

- invert levels, ground elevations and cross sections of the Sortie's final stretch (ca. $1300 \mathrm{~m}$ long) come from a detailed survey, provided by HERA; 

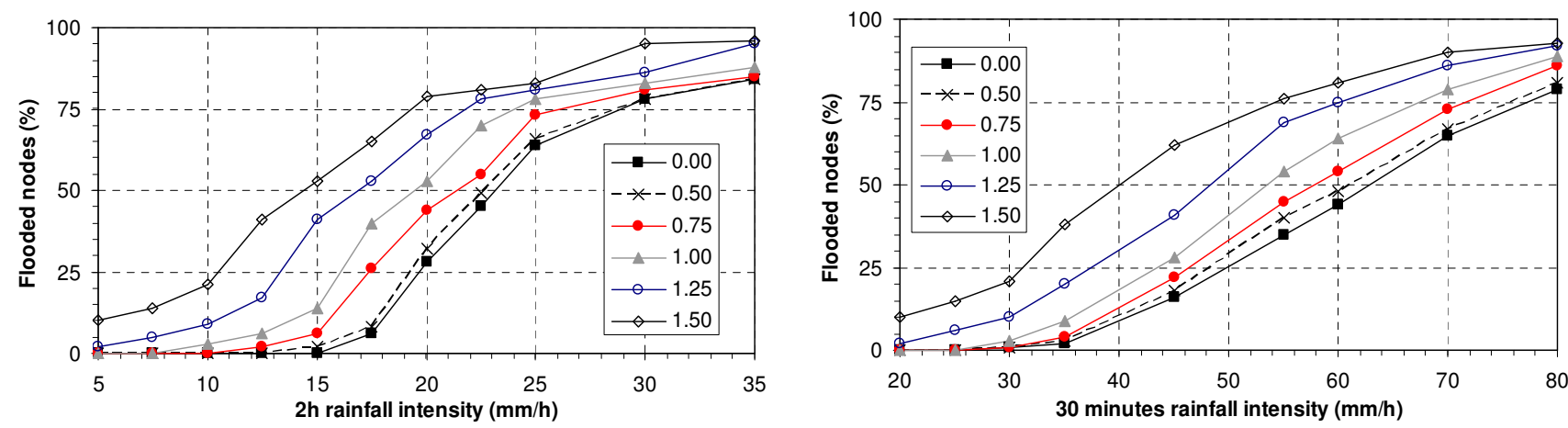

Fig. 7. Percentage of network nodes flooded as a function of constant rainfall intensity (Duration: $2 \mathrm{~h}$, left panel; $30 \mathrm{~min}$, right panel) and of sea level at network outfall, supposed variable between 0 and $1.50 \mathrm{~m}$ a.s.l.

- ground elevations for urbanized area and inland zone come from the Technical Regional Map;

- land use has been inferred by aerial photo at first and later adjusted during the model calibration process.

HERA also provided rainfall data, the rain gauge is located nearby the Sortie catchment $(3 \mathrm{kmSE})$ and the sea water level data is measured immediately downstream of the Sortie outfall.

In Fig. 5 the position of the tide gauge at the study site is shown.

\section{Methods}

The analysis has been based on the methodology proposed by Hawkes (2008), associating standard conditions of precipitation and sea level to a certain degree of damage (inconvenience) due to flooding events.

The numerical model simulates runoff on the whole drained catchment and flows through the entire drainage network, but the flooding effects analysis is focused just on the 60 ha urbanized area along the coastline.

InfoWorks CS, as do the majority of numerical models for drainage networks, assumes that the network is made of point elements (nodes) connected by linear elements (conduits). Nodes are the points where runoff generated on the basin's surface enters the network, but also the points where, in case of surcharge, water level may exceed ground elevation and flow out of the network (flooding).

When this happens, the model (here adopted in 1-D version) has two options:

- the flooded water volume is lost;

- the flooded water volume is stored in a hypothetic cone rising over the node. When the network is no longer in surcharge condition, the cone empties and the flooded volume re-enters into the network.
Since this analysis was limited to the 1-D functions of the software and being not able to assign a realistic street flooding depth (due to the cone schematization), the severity of flooding effects has been determined by the percentage of nodes among those present in the urbanized area, which experienced flooding.

Once such flooding severity index had been defined, it was related to the two climatic driving forces: rainfall and sea water level at the network outfall.

It is well known that the effects of precipitation on a catchment depend on the duration, which may be critical for a given area, according to its hydrological characteristics and slope. Therefore two critical durations have been identified, one $(2 \mathrm{~h})$ associated with the entire basin drained by Sortie, the other (equivalent to $30 \mathrm{~min}$ ) related to the urbanized area only.

\section{Results}

Based on the two critical durations previously defined, two different groups of numerical simulations were performed. For each group, a set of constant intensity rain events, has been simulated over the whole catchment. Each set was repeated by varying the condition of the sea level at the Sortie outfall. For each single simulation the percentage of flooded nodes was found and from the combination of such percentage with the relative rainfall intensity and sea level at the outfall, it was possible to generate the curves shown in Fig. 7. Subsequently, the interpolation of the Fig. 7 curves generates the curves shown in Fig. 8, shown as isolines of equal flooding effect severity (based on the percentage of nodes that are experiencing the flooding) as a function of average rainfall intensity and sea water level at network outfall.

The same results can be seen in Fig. 9, shown in terms of return periods of each variable, according to the values presented in Table 1.

Figure 9 shows for instance that an equal flooding severity can be caused by a 10 years Return Period rainfall and a 

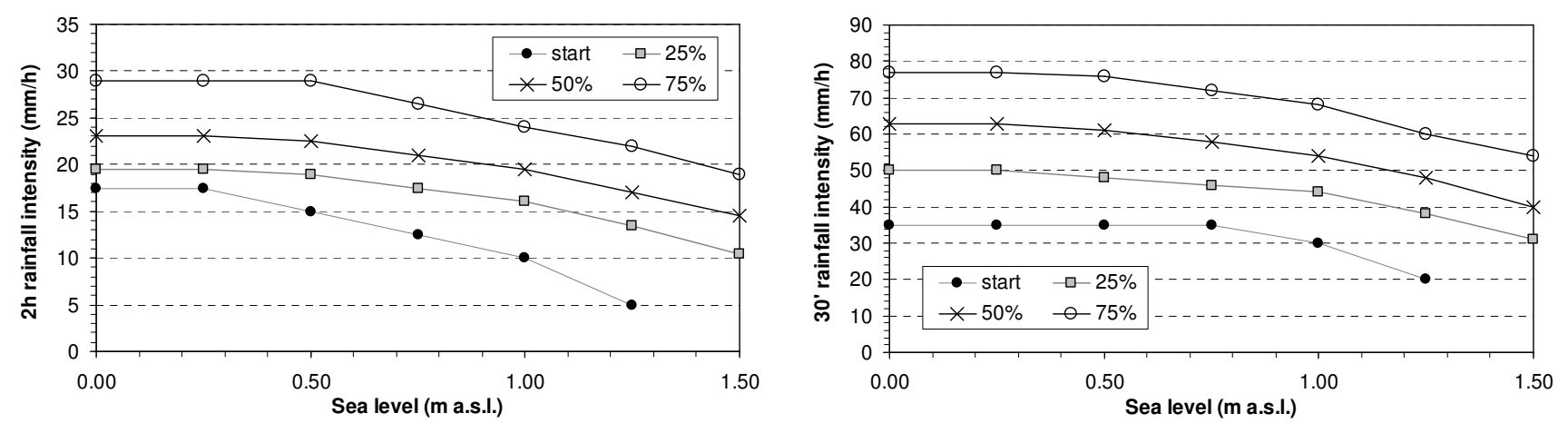

Fig. 8. Isolines representative of an equal percentage of flooded nodes as a function of average constant rainfall intensity (Duration: $2 \mathrm{~h}$, left panel; $30 \mathrm{~min}$, right panel) and of sea level at network outfall. "Start" condition represents the threshold condition right before flooding occurs.
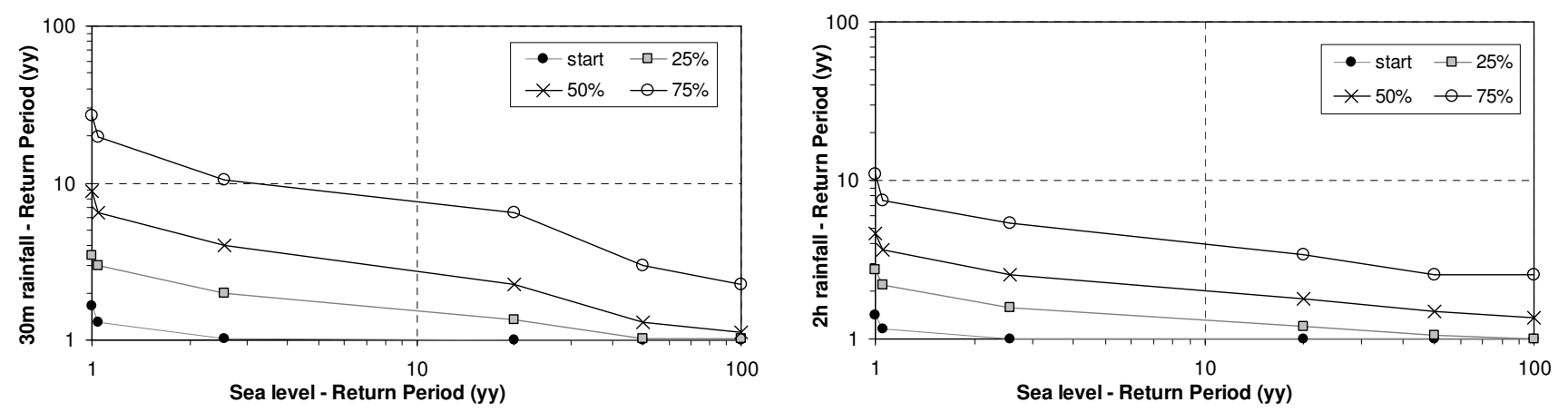

Fig. 9. Isolines representative of an equal percentage of flooded nodes presented as a function of rainfall intensity and sea level return periods. "Start" condition represents the threshold condition right before flooding occurs.

$2.5 \mathrm{yr}$ RP sea water level as well as a $7 \mathrm{yr}$ RP rainfall and a $20 \mathrm{yr}$ RP sea water level.

A preliminary analysis on correlation between rainfall and sea water level was performed on the data used in the analysis. Dependence properties and measures of association between the variables considered have been investigated in terms of copulas. The estimated value of the non parametric Kendall's tau correlation coefficient is 0.254 .

Since the dependence between the two variables is not trivial (neither independent, nor fully dependent), then they are suitable candidates for a joint probability analysis. For each variable a Kernel estimate of the distribution was performed. We arbitrarily have chosen several well known families of copulas, featuring a wide range of dependence, and covering most applications found in the hydrological applications (Salvadori et al., 2007); we have. so, decided to test the most common Archimedean copulas used in hydrology (Salvadori et al., 2007), because they are also the simplest. The selected tested copulas are: Clayton, Frank, Gumbel and Ali-MikhailHaq copula.
Then, by using two different goodness-of-fit criteria, the classical maximum likelihood and the Akaike and Bayesian information criteria we have selected the most appropriate copula. The best copula seems to be the Frank and the estimated dependence parameter a is equal to 2.88 .

Once the flooding severity isolines had been drawn (Fig. 8) according to the synthetic boundary conditions previously mentioned, the whole system had been simulated using rainfall data and sea water level at the network outfall actually recorded throughout year 2009. During that year 69 rain events were detected, of which only 4 exhibited episodes of flooding. The most serious among them, according to the simulation results (Fig. 10) would have affected $9 \%$ of the network nodes falling within the urbanized coastal area (see Table 2 for conditions).

It is interesting to notice that during the events II and IV the precipitation was small, but the swl at the outfall was high, causing problems of discharge flow to the sea. These conditions are typical during Scirocco storms from South.

All the simulated events and their respective effects were then analyzed on the basis of the average rainfall intensity and sea water level associated with them. Average rainfall 
Table 2. Conditions during the 4 events in the year 2009 causing urban flooding. B and S in the column Wind indicates the storm typology, respectively Bora and Scirocco.

\begin{tabular}{llccrr}
\hline Event \# & Date $[\mathrm{dd} / \mathrm{mm} / \mathrm{yy}]$ & Wind & Sortie Swl $[\mathrm{m}]$ & 30' rainfall int. $\left[\mathrm{mm} \mathrm{h}^{-1}\right]$ & 2 h rainfall int. $\left[\mathrm{mm} \mathrm{h}^{-1}\right]$ \\
\hline I & 25 Jan 2009 & B & 1.30 & 16.94 & 7.37 \\
II & 3 Feb 2009 & S & 1.50 & 4.00 & 1.99 \\
III & 30 Aug 2009 & B & 0.28 & 33.16 & 11.02 \\
IV & 31 Dec 2009 & S & 1.42 & 5.95 & 2.82 \\
\hline
\end{tabular}

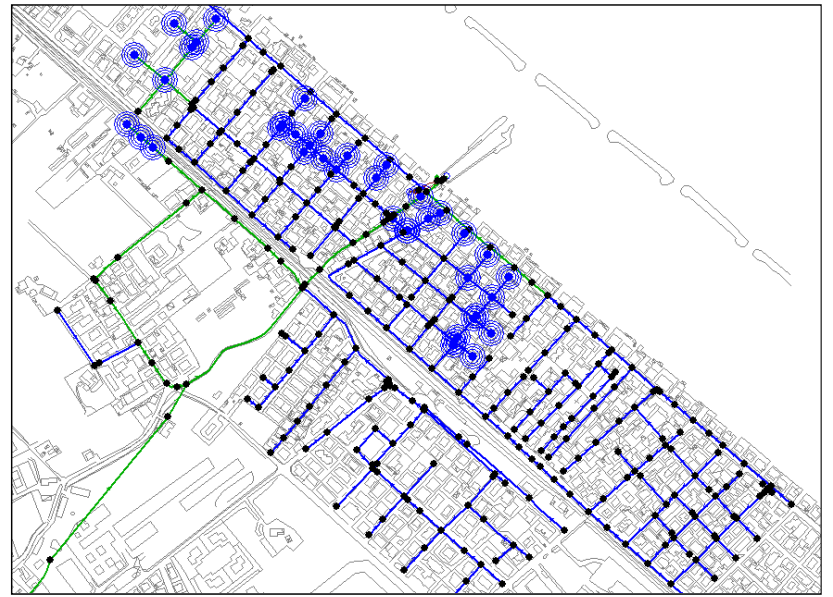

Fig. 10. Flooded network nodes resulting from the simulation of the most severe event occurred in year 2009 (flooded nodes percentage equal to $9 \%$ ) (Data 3 February 2009, swl $=1.50 \mathrm{~m}$, 30' rainfall intensity $=4 \mathrm{~mm} \mathrm{~h}^{-1}, 2 \mathrm{~h}$ rainfall intensity $=2 \mathrm{~mm} \mathrm{~h}^{-1}$ ).

intensity has been separately classified according to the two different critical durations, previously identified.

This procedure has lead to the definition of Fig. 11, where each rainfall event occurring in the year 2009 is represented by a point, whose different marker highlights whether the numerical model detects flooding or not. For the four events where flooding occurred the percentages of flooded nodes is indicated in brackets.

The results show that the lines generated by interpolating the simulations output based on fixed rainfall and sea conditions (Figs. 7 and 8), can satisfactorily predict the effects produced by a long time real data series.

Just a slight underestimation case appears for one of the real events that resulted in $5 \%$ of nodes flooded, when classified according to the two-hour duration.

Since no direct measurement of flood is available for the study site, possible information concerning floods were retrieved by HERA and the local fire department, in order to validate the results obtained.

HERA database refers to emergency calls for the following reasons: basement flooding, backwater effects in the drain; misfunctioning of the combined or storm sewer system.
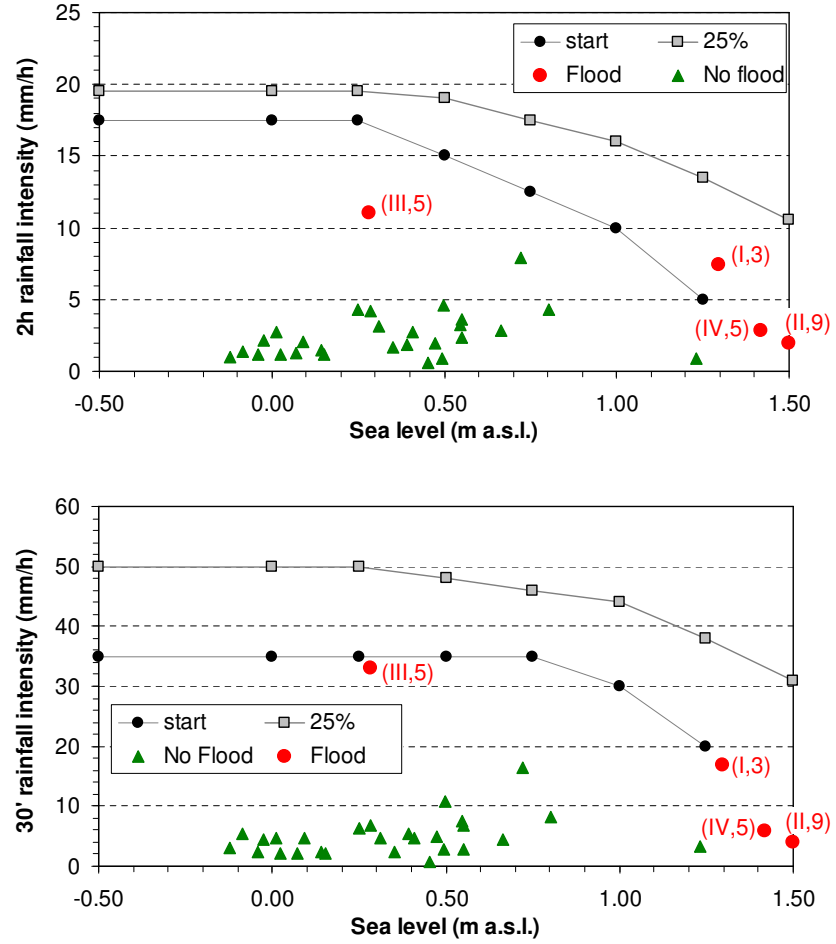

Fig. 11. Rainfall events occurred during year 2009 (classified according to their average intensity on $2 \mathrm{~h}$ : top panel and $30 \mathrm{~min}$ : bottom panel) for which the numerical simulations exhibited or nonexhibited flooding, compared to the previously determined isolines of severity. In brackets the event \# and the percentage of flooded network nodes.

Fire Department database refers to emergency calls for water damages and flooding or storm surge.

Emergency calls were detected in both databases for each of the four events listed in Table 2.

Even though no information concerning the event magnitude is available from such sources, the comparison between flood data and simulation exhibit a positive preliminary validation. 


\section{Conclusions}

The work has analyzed the behaviour of a portion of the drainage network of a city located on the sea, Rimini, considering not just the effects due to rainfall events, but also to the different conditions of sea water level at the network outfall.

The analysis has been carried out by means of numerical hydraulic simulations of the drainage system, which allowed the percentage of network nodes that may experience flooding to be estimated, as a function of given rainfall and sea conditions. Isolines representing equal severity in terms of urban flooding have been created from the interpolation of the simulations results, showing a combined (rainfall-sea level) risk for the sewer system under consideration. The presented approach is therefore an attempt to identify the critical hydraulic states of a sewer system, not only in terms of possible rainfall events, but also jointly considering the conditions of the receiving water body.

Simulation results met positive validation when compared to HERA and Fire Department emergency calls' databases.

This simplified methodology appears both effective and interesting, especially in urban areas, where the deterministic analysis of flood events should rely on a 2-D surface model, whose applicability requires a highly detailed ground model. The method can be extended and applied to similar drainage systems in coastal areas, and may turn useful during both the design and the operation and management phases. Since Fig. 9 allows for the assessment of flooding severity under a wide range of conditions, possible climate change effects may be assessed as well.

A preliminary analysis on variable correlation and joint probability estimation between rainfall and sea water level through copula, based on a short data set, has also been presented. A more detailed analysis and discussion on the joint probability will be the topic of future research.

Acknowledgements. The study has been carried out within the research project "New numerical and experimental approach for the assessment of flooding risk of urban area in coastal zones". British-Italian Partnership Programme for Young Researchers 2007/08 between Universities of Bologna and Newcastle (UK) - Financed by the Italian Ministry for University and Research and by the British Council. The research was partially supported by the project PRIN 2008 "Tools for the assessment of coastal zone vulnerability related to the foreseen climate change" financed by the Italian Ministry of University and Research (MIUR). The authors are very grateful to Marinella Masina for the help in the preliminary copula analysis and to Attilio Castellarin for the useful discussion on rainfall analysis.

Edited by: E. Morin

\section{References}

Archetti, R.: Quantifying the evolution of a beach protected by low crested structures using video monitoring, J. Coast. Res., 25, 884-899, 2009.

Cappietti, L., Clementi, M., Aminti, P. L., and Lamberti, A.: PilingUp And Filtration At Low Crested Breakwaters Of Different Permeability, ICCE2006, XXX Int. Conf. on Coast. Eng., San Diego, USA, 4957-4969, 2006.

Cesini, D., Morelli, S., and Parmiggiani, F.: Analysis of an intense bora event in the Adriatic area, Nat. Hazards Earth Syst. Sci., 4, 323-337, doi:10.5194/nhess-4-323-2004, 2004.

Di Baldassarre, G., Castellarin, A., and Brath, A.: Relationships between statistics of rainfall extremes and mean annual precipitation: an application for design-storm estimation in northern central Italy, Hydrol. Earth Syst. Sci., 10, 589-601, doi:10.5194/hess-10-589-2006, 2006.

Hawkes, P. J.: Joint probability analysis for estimation of extremes, J. Hydraul. Res., 46, 246-256, 2008.

Hawkes, P. J., Gouldby, B. P., Tawn, J. A., and Owen, M. W.: The joint probability of waves and water levels in coastal engineering design, J. Hydraul. Res., 40, 241-251, 2002.

Hawkes, P. J., Gonzalez-Marco, D., Sánchez-Arcilla, A., and Prinos, P.: Best practice for the estimation of extremes: A review, J. Hydraul. Res., 46, 324-332, 2008.

Huber, W. C. and Dickinson, R. E.: Storm Water Management Model, User's Manual, EPA/600/3-88/001a (NTIS PB88236641/AS), U.S. EPA, Athens, GA, 30605, 1988.

Kroon, A., Aarninkhof, S. G. J., Archetti, R., Armaroli, C., Gonzalez, M., Medri, S., Osorio, A., Aagaard, T., Davidson, M. A., Holman, R. A., and Spanhoff, R.: Application of remote sensing video systems for coastline management problems, Coast. Eng., 54, 493-505, 2007.

Martucci, G., Carniel, S., Chiggiato, J., Sclavo, M., Lionello, P., and Galati, M. B.: Statistical trend analysis and extreme distribution of significant wave height from 1958 to 1999 - an application to the Italian Seas, Ocean Sci., 6, 525-538, doi:10.5194/os-6-5252010, 2010.

Masina, M. and Ciavola, P.: Analisi dei livelli marini estremi e delle acque alte lungo il litorale ravennate (Analysis of extreme sea levels and high tides along the Ravenna coast), in Italian, Studi Costieri, 18, 84-98, 2011.

Peel, M. C., Finlayson, B. L., and McMahon, T. A.: Updated world map of the Köppen-Geiger climate classification, Hydrol. Earth Syst. Sci., 11, 1633-1644, doi:10.5194/hess-11-16332007, 2007.

Salvadori, G., De Michele, C., Kottegoda, N., and Rosso, R.: Extremes in nature, An approach using copulas, vol. 56 of Water Science and Technology Library, Springer, 2007.

Tawn, J. A. and Vassie, J. M.: Spatial transfer of extreme sea level data for use in the revised joint probability method, Proceedings - Institution of Civil Engineers, Part 2, Research and theory, 89, 433-438, 1990. 